\title{
The nature of Nature: conflict and consensus in fisheries management
}

\author{
M. Estellie Smith \\ Dept. of Anthropology, State Universily of New York, \\ Oswego, NY 13126, U.S.A.
}

Accepted April 4, 1995.

Smith M. E. Aquat. Living Resour., 1995, 8, 209-213.

\begin{abstract}
Using the example of the New England Regional Fisheries Management Council and its attempts to manage the fisheries in its area, this paper argues that differences in the way Nature "operates" constitutes a major source of divisiveness between, on the one hand, those members (and other managers in, say, government) who use linear modeling systems and, on the other hand, the majority of those in the commercial fishing sector who, intuitively, have cast nature in those non-linear terms currently being explored in the Chaos paradigm. Since these two different models have not been explicitly addressed, there is a history of members on each side accusing those on the other of bargaining in poor faith and lacking an adequate understanding of the resource. The thesis of the paper is that making explicit these underlying cognitive modes would provide more "common ground" for addressing management problems in such co-management arenas as the fishery management councils and elsewhere.
\end{abstract}

Keywords: Chaos, fisheries management, co-management councils.

La nature de la Nature: conflits et consensus dans la gestion des pêches.

Résumé

En s'appuyant sur l'exemple du Conseil Régional de Gestion des Pêches de Nouvelle Angleterre et sur ses essais en matière de gestion des pêches dans son aire géographique d'influence, cette étude montre que les différences dans la façon de percevoir les actions de la nature constituent une source majeure de divergence entre, d'une part, ceux des acteurs (et autres gestionnaires type gouvernements) qui usent de systèmes de représentation linéaire et, d'autre part la majorité de ceux qui, dans les pêches professionnelles, intuitivement, attribuent à la nature des effets non linéaires tels que les explore la théorie du chaos. Puisque que ces deux conceptions différentes n'ont pas été explicitement exprimées, il existe une histoire des membres dans chaque camp accusant l'autre camp d'approche réductionniste, passant à côté d'une compréhension exacte de la ressource. La thèse défendue ici est qu'en posant cela de façon explicite et en soulignant les modes cognitifs on pourrait fournir davantage « de bases communes " pour aborder les problèmes de gestion de façon plus proche des formes de co-gestion que des conseils de gestion des pêches ou autres institutions équivalentes.

Mots-clés : Chaos, gestion des pêches, conseils de co-gestion.

\section{WHAT'S THE PROBLEM?}

In the current process of coping with the crisis in marine fishery resources, the United States has developed a management technique centered around the creation of eight regional fishery management councils whose primary function is to produce plans for both protecting and enhancing utilization of marine resources. A portion of council positions is filled by individuals whose membership is mandated (e.g. the director of fisheries for each constituent state); other members are selected for their expertise or working knowledge. Despite regional variation in the composition of such councils, members 
are predominantly drawn from, on the one hand, public sector personnel (e.g. administrators, scientists, technicians) and, on the other hand, the user groups - particularly members of the commercial fishing industry. Legislation establishing this mode of management mandates that councils (and the federal personnel who must "sign off" on plans) take into account "all relevant biological, political, economic, and sociocultural factors" and utilize "the best scientific data available" to write (and, when necessary or feasible) rewrite the plans.

Public policy theory argues that the combination of the differing goals of such diverse groups and the assortment of special knowledge and practical expertise at a negotiating table, will result in consensual management programs with which most people can live most of the time. Hopes for this type of management process were high at the outset (implemented March 1, 1977) since, despite all the differences of opinion, complexities, and uncertainties, all participants in the management process were and are agreed on one thing: steps must be taken to maintain the resources at a viable level to sustain the food species for future generations.

The history and results of the process since regional council management was initiated have satisfied few. Charges of over-management compete with countcrclaims of inadequate regulation, excessive sensitivity to political pressure at all Jevels, the vested interests of commercial sector representatives on the councils, the greed that puts profits first, and so on.

However, this particular management format is an exercise in consensus- building among individuals who (1) have competing analyses of the data (often minimal and, in any case, necessarily dated in the volatile world of the fish stocks), and (2) who differentially prioritize the various management factors, e.g. goals. Though all plans assume rules will be enforced and/or obeyed, those at the negotiating table agree to plans that, in the eyes of the commercial fishermen, lack legitimacy and, further, funds for monitoring are, by definition, inadequate; without wide-scale acceptance of the plans by the commercial sector, enforcement monies can never match monitoring needs.

But the more that believe that the plans make no sense in "the real world", the more common will be violations. Thus, for example, Norway has challenged the international ban on whaling on the grounds that such a ban lacks legitimacy and imposes excessive social costs. Here is a prime example of a case of informed people with the same goals - preservation of marine resources - being in disagreement; one party has determined it will abrogate the rules previously negotiated and that other still accept. Similarly, many commercial fishermen will refuse to support management plans that seem to them to defy their own knowledge of the resource and their "common sense".
This paper argues that the negotiating participants - in all sectors and at all levels of the management process - are divided by differing views of the nature of Nature. These views are axiomatic but significantly inform each participant's approach to (1) what constitutes critical or relevant data; (2) how to interpret those data; (3) how to design crisis-appropriate responses. Such views are variously acquired and systemically integrated as one moves through life, making a serjes of commitments to various modes of thinking about the world in order to devise decision-making strategies consonant with (or at least are not in opposition to) those held by the primary groups with whom one lives and works.

The consequences of this difference: (1) Different information is gathered or (2) even the same data are analyzed differently. This results in sharply divergent perceptions of how and sometimes even what to manage - how to make decisions now that will produce intended results rather than unintended consequences. There are also longer-term effects: Each group increasingly sees as "the other side" as not bargaining in good faith, lacking in good will, and lacking an ability to come to grips with basic needs and critical parameters of the fisheries and the industry.

\section{Consensus management}

Axiomatic models provide the yardsticks individuals and groups use when measuring "good" versus "bad management". However, fundamental differences in these models and the fact that they are rarcly made explicit create a chasm across which dialogue is difficult, if not impossible. "My position" (whether derived from scientific research or practical experience) is grounded in common sense and will surely generate sound plans; "your position" is too general (or too narrow), complex (or too simple), rigid (or ad hoc), costly (or inadequately funded for proper implementation), ignores the human element (or is too vulnerable to manipulation in the political and/economic arcnas). The extent to which a group whose members hold diverse viewpoints can produce a workable management plan that does not violate their respective axiomatic models (but need not fully reflect them), determines the degree to which industry members cooperate in making the plans work. If or when management programs finally are implemented, such deeply held but rarely stated world views - what anthropologists label cognitive modes - are liable to lead members of, especially, user group(s) enthusiastically endorse, reluctantly comply, or rigorously resist regulations.

It will also influence the extent to which fishery managers perceive the need to continue "fine tuning" the plan, a process that frequently results in continued modification. This, however, is sometimes perceived as "crisis management". Not uncommonly, once implemented, plans are subjected to a series of emergency actions consequent on ncw data that 
indicates overfishing of juveniles or shortfalls in landings. User groups see the process - sometimes correctly - as a bewildering and contradictory flow of rules and regulations and most participants expect management plans likely to fall short, overshoot, or careen wildly, producing devastating, unintended consequences for both human and fish populations (cf. M. E. Smith, 1982).

I have no intention on arguing for one or another view of the nature of Nature. The point of this paper is, rather, to stress that different views do exist and do play a determining role in each step and every aspect of the management process. If I emphasize the utility of the nonlinear over linear model it is to emphasize that the former model is, intuitively, that which most closely approximates the industry view of Nature - though such views are often dismissed by linear modelers as "uninformed" or "unscientific". If it can be accepted that the chaotic view has legitimacy, I believe it will make for a more productive dialogue among all participants in the process.

\section{Natural systems: linear and nonlinear}

It is when working in the realm of second-guessing naturc, particularly the fish stocks, that we are able to see this major distinction emerge. There are, on the one hand, those who view Nature in classic Newtonian terms; on the other hand, there are those whose understanding of natural processes is strikingly parallel to the model being suggested by the newly emerging science of Chaos. Both admit the existence of causal chains but adherents of the first position model the world in terms of linear relationships; those of the second, in nonlinear interweavings.

To over-simplify for illustrative purposes: One group, the majority of biologists, economists, and ecologists - scientists and technical experts in marine research studies and in the state/federal agencies concerned with fisheries - see Nature as (1) a system and (2) a system in which there is periodic order. Essentially, the study of such a system depends on looking at it locally, studying various species, year classes, sub-regions within the marine econiche, the various ports and their landings, etc. It involves defining perimeters and parameters, identifying relevant variables and utilizing differential equations to describe processes that change smoothly over time. In such a system, one must monitor and measure within a context that stays constant from Time Measurement X1 to TM X2, X3, etc. Lending itself to the perception of the rightness of such approaches to understanding the workings of Nature is a tendency among fishery managers to speak of the reproductive process of the stocks as if there were neither interactions among overlapping generations, nor unique environmental events affecting generations differently. It is assumed that one can directly identify the relationship between the number of, say, herring or cod at Time $\mathrm{X} 1$ and the number for Time $\mathrm{X} 2-i$.e. to express stock dynamics as if the Time $\mathrm{X} 2$ population is a simple function of the Time XI population (for a challenge to such population modeling see May, 1976).

Perhaps the classic expression of the linear view of population dynamics - i.e., the view that the nature of Nature is ordered, balanced and in dynamic equilibrium - was given by J. Maynard Smith (1968) whose position was that populations either remain relatively constant or regularly vary around some presumed equilibrium point. In the case of commercial fisheries, biologists frequently assume that fishing effort accounts for deviations of real populations from this model and, in the last decade especially, have moved to sustain the stocks by attempting to regulate human predation. As James Gleick put it: In a real world system an observer would see just the vertical slice corresponding to one parameter at a time. He would see only one kind of behavior - possibly a steady state, possibly a 7-year cycle, possibly apparent randomness. He would have no way of knowing that the same system, with some slight change in some parameter, could display patterns of a completely different kind (1987:73). In this cognitive mode, macro-level phenomena are "explained" in terms of a reductive or analytic analysis grounded in the perception that whatever is defined as the observable whole is "the natural result of the interaction between the externally related "parts" "(Madison, 1990: 91).

Members of the second group - most often industry members, especially fishermen and their families, buyers, and processors - see Nature as non- random ("Things don't just happen - there's always got to be a reason") but unpredictable ("If I knew everything that was going to make one trip a winner and another a loser, I'd be God"). Natural processes are complicated and dynamic; causal relations and sequential patterns (if they can be charted at all) can stretch over so long a period that they appear aperiodic. Data selected for review often appear random, disordered, non-causal in their linkages, and chaotic. The world (the fish stocks, the weather, the market, the fishery management process, whatever) is continually susceptible to disequilibrium rather than in a linear mode where entropic systems are in a constant search for equilibrium. This is a perspective beginning to find some support among scientists (see, e.g., Allen and McGlade, 1987, n.d.; Wilson and Kleban, 1992; Gilbertson, 1993). Attempts to understand population dynamics (or the weather, economic activity, or most forms of human behavior for that matter) in terms of linear relationships that can be captured on a straight line graph can be counterproductive. In the case of fisheries management, it may not be a feasible model for managing the resource and has certainly failed to win cooperation from the industry. Yet, those critically responsible for final plan production - in translating the variety of discussions and hearings that are preliminary to plan submission for federal approval and thus also underwrite their final rejection/approval 
of plans - are, for the most part, linear modelers. They approach natural processes, as well as the human activities and decisions that affect those processes, with the kinds of assumptions both preferred by and required of those who occupy positions within what social scientists label "rational bureaucracies" - management structures in which public policy decisions are, ideally, made in an objective and non-personal fashion.

Although a recognition of nonlinear processes has only been achieved in the last two decades, it's a good guess that industry members (especially fishermen), intuitively long have organized their knowledge of Nature in terms of nonlinear relationships. They, like Chaos theorists, argue that the fishery dynamics unfold in a non-random but unpredictable fashion - "unpredictable", however, no model can take into account the vast universe of (ultimately) systemic-significant perturbations. Highly determining in both calculated and real outcomes, these are elements ignored or dismissed in the decision-making involved in identifying relevant current data or model configurations. We all learned the principle as school children: "For want of a nail, a shoe was lost; for want of a shoe, a horse was lost; for want of horse, a rider was lost; for want of a rider, a message was lost; for want of a message, a battle was lost; for want of a battle, a war was lost; for want of a war, a kingdom was lost - and all for want of a nail".

In a nonlinear universe no input or output can be prejudged to be "irrelevant", or "trivial", and little if anything can be set aside in a category labeled "All things being equal". Not only does "Every little movement have a meaning all its own" but, more importantly, as the "meaning" of that small event or new input moves through successive layers of evermore extensive networks, its significance snowballs; its potential to alter future events or characteristics of the system intensifies. When fishermen and shore- side industry personnel make decisions relative to resource exploitation - decisions that affect the extent to which they violate or comply with regulatory regimes - they are seeing each trip, each season, each year's stock as part of a system that is complicated and aperiodic, almost but never quite repeating itself over time. It is a system in which small differences produce major variations ( $c f$. Lorenz, 1979).

It is clear that the distinction between those arguing for linear or non- linear views of nature is nol based on a distinction between "scientists" and "entrepreneurs", "pure theory" and "dirty practice", those who are smart and dumb, are self-serving (because, sneer the fish managers, they can't see beyond the immediate trip's payoff) or altruistic (but only, snarl the fishermen, because the incomes of the "fishcrats" don't suffer if they make a bad choice). Further, people can and do switch from one to another depending on the topic being examined; some economists argue for the "random walk" theory of the market (e.g., Paulos, 1994) but this does not lead them to select investments for their retirement monies by throwing darts at stock listings in the Wall Street Journal. Finally, neither model excludes components of the other; e.g., the Chaos model does not deny the basic, systemic order of linear thinking, only the difficulty (perhaps impossibility) of including all the significant variables in a complex universe that necessitates accepting that all management involves uncertainty - that Simon's satisficing principle (1979) applies as much to assessing possible outcomes as deciding when one has sufficient information to make a choice. A return to negotiating fisheries management.

What happens when people holding these differing vicws meet and attempt to achieve consensus on managing the fisheries?

Linear-oriented analysts believe that the significant components of a system can be identified so completely that they can identify the appropriate input and predict the results. Those relying on the nonlinear approach argue that we can never identify an entity's full synergistic potential - the entity is "sensitive dependent" on initial conditions, and total knowledge is impossible. The first expect a continuing process of "fine tuning the system"; the second are prepared to "play it by ear". These expectations, grounded in axioms about the nature of Nature, color what various participants think the other fellow is talking about, what "we have agreed on", and, inevitably, leads both to attempts to alter "final" plans (on the basis that their content was not what had been negotiated) and a position by fishermen that the plans are unrealistic, thus justifying "breaking the rules".

\section{CONCLUSION}

This discussion has been presented not to argue for the strength of weakness of two different models but to demonstrate that various conceptual cores are part of the "intellectual baggage" that each and every participant in every phase of the management process brings to negotiating, planning and implementing fishery plans. This paper argues that different cognitive models do exist, do play an important role in the way people think about the world, affect decision-making, and what people do or do not do.

If the existence of these subtle, covert models are sufficient to cause our attempts to deal with the problems to become subverted, perverted, or fail, I think it important to take the time to make them explicit. It is not, as one fisheries manager said, "a lot of "feely-goody" nonsense and waste of time" - if only because of the extent to which such differences lead to confrontation on issues that, in many cases, are only surrogates for deeply held convictions relating to how to make sense of the world. It's not easy to question those things that "everyone knows" and that are taken "as given"; far from being commonplace, ordinary, and trite, they frequently embody complex, sometimes contradictory components. And even after one starts 
thinking about them, it can remain difficult to express them lucidly - to Self and, especially, Other. In a world where attempts to manage are expanding, it is increasingly obvious that it really does matter how well non-common "group think" grapples with common problems. It is critical to address the reasons why, as one long-time fishery council member despairingly once said to me "Sometimes it seems the more we try, the worse things get".

\section{Coda}

In the final analysis, every management scheme is measured not by its internal consistency and modeled predictive success but by the extent to which people comply with it. And a willingness to comply is usually a general acceptance, grounded in a perception that it "makes sense". It is not only fishermen who refuse to follow the rules if, too much of the time, these strictures seem to violate both axioms of "common sense" and practical needs.

Whether a chaotic modeling of the fishery stocks is better or worse or even practical is one problematic of management. Far less problematic is the application of the chaos model to the process of fishery management itself. As it stands now, fish managers are being forced to "return to the drawing board" continually as the volatile world of the commercial fisheries force us to recognize that our attempts at management are not working as planned. The consequences are constant perturbations introduced into an exploitive system that, in addition to being driven by market economics, political needs, and an ever-expanding technology, is already marked by Nature's own systemic sensitivities and unpredictability.

\section{REFERENCES}

Allen P. M., J. M. McGlade 1987. Modcling complex human systems: a fisheries example. Europ. J. Operations Res. 39, 2, 147-67.

Allen P. M., J. M. McGlade, n.d. Managing complexity: A fisheries example. Report prepared for the Global Learning Division of the United Nations University. Int. Ecotechnology Res. Ctr.

Gilbertson N. 1993. Chaos on the commons. MAST 6, 74-91.

Gleick J. 1987. Chaos: making a new science. Viking Penguin, New York.

Lorenz E. 1979. Predictability: does the flap of a butterfly's wings in Brazil set olf a tornado in Texas? Annual meeting of the AAAS, Washington D.C.

Madison G. G. 1990. Bctween theory and practice: Hayck on the logic of cultural dynamics. Cult. Dynamics 3, 1, 84-112.

May R. 1976. Simple mathematical models with very complicated dynamics. Nature 261, 459-67.

Simon H. A. 1979. A behavioral model of rational choice. In: Models of thought, H. A. Simon ed. Yale Univ. Press, New Haven, 1-6 (orig. publ. 1955).

Smith J. M. 1968. Mathematical ideas in biology. Cambridge Univ. Press, Cambridge, England.

Smith M. E. 1982. Fisheries management: Intended results and unintended consequences. In: Modernization and Marine Fisheries Policy, J. Maiolo, M. Orbach eds. Ann Arbor Science Publ. Ann Arbor, 57-94.

Wilson J. A., P. Kleban 1992. Practical implications of chaos in fisheries: ecological adapted management. MAST 51, $67-75$. 